Methods This descriptive study was carried out on a random sample of 638 injured children aged 15 or less who were admitted to the emergency units of Valiasr and Moosavi Hospitals from June 2008 to March 2009 in Zanjan. Information on demographics, and socioeconomic factors such as parental education and family income was gathered.

Results The major causes of injuries were motor vehicle crashes $(36 \%)$, falls $(34 \%)$, falling objects $(13 \%)$, burns $(12 \%)$ and poisoning $(6 \%)$. Three hundred ninety one $(61.3 \%)$ of injured children were male and 247 (38.7\%) were female. The mean age of the injured children was $7.8 \pm 4.2$ years. Motor vehicle crashes were more common among older children, while burns and poisoning were common in younger children. Most injuries in boys than girls occurred between 10 and 15 years old (45\% vs 30\%, p<0.0001). Injuries were more prevalent in children whose father was a manual worker or mother was a housewife. The level of education of both parents was low in most cases. More than half injuries occurred for children who were living in a low-income family. These patterns were observed for all types of injuries.

Conclusion The results highlight the need for targeted injury prevention efforts among children and families with a low socioeconomic status.

\section{P1-470 SOCIOECONOMIC DETERMINANTS OF PASSIVE SMOKING DURING PREGNANCY AND BIRTH WEIGHT OF NEWBORNS}

doi:10.1136/jech.2011.142976g.59

S Mazloomzadeh, ${ }^{*}$ B S Abrishami, F Moezzi. Zanjan University of Medical Sciences, Zanjan, Iran

Introduction It is well known that maternal smoking during pregnancy results in adverse reproductive outcomes. However, the impact of passive smoking on fetal growth is less clear. The aim of this study was to determine the socioeconomic status of pregnant women who were exposed to tobacco smoke and its influence on birth weight of their newborns.

Methods This descriptive study was conducted on 450 nonsmoker women with singleton live births. Data on demographic, social and reproductive characteristics were obtained. Women were asked for details of their exposure to smoking at home or in the workplace. Data were analysed using $\chi^{2}$, independent t-test, ANOVA and Regression methods.

Results One hundred seventy seven women (39.3\%) were exposed to tobacco smoke. A significant association between passive smoking and socioeconomic indices such as the educational level and the occupation of the women and their spouses was found. The proportion of passive smokers was lower in families with higher income. Infants born to passive smokers weighed a mean of $28 \mathrm{~g}$ lighter than those born to non-passive smokers $(p=0.53)$. The mean birth weight of infants born to women whose husbands smoked more than 10 cigarettes per day was $3.110 \mathrm{~kg}$, resulting in a greater difference of $49 \mathrm{~g}$. Conclusion The results provide no significant decrease in birth weight of infants born to passive smokers in comparison with nonpassive smokers, which may be related to a lower extent of exposure in this population.

\section{P1-471 FACTORS ASSOCIATED WITH EXCLUSIVE BREASTFEEDING TO 6 MONTHS AMONG CANADIAN INUIT: RESULTS FROM THE INUIT HEALTH SURVEY FOR CHILDREN}

doi:10.1136/jech.2011.142976g.60

K Mclsaac. * University of Toronto, Toronto, Canada

Introduction Inuit Canadians are less likely to initiate breastfeeding compared to other Canadians, although they are more likely to practice exclusive breastfeeding to 6 months. The objective of the present research is to identify factors associated with practicing exclusive breastfeeding to 6 months among Inuit Canadians.

Methods We used the Inuit Health Survey for Children, a crosssectional, population based survey of pre-school aged Inuit children to identify factors associated with exclusive breastfeeding to 6 months. The survey was administered in 16 communities in the territory of Nunavut in 2007 and 2008. Caregivers of Inuit children ages 3 to 5 who lived in a participating community were randomly selected to complete the interviewer- administered questionnaire. Of the 537 caregivers successfully contacted, 388 participated and 242 initiated breastfeeding and were included in our analyses. We used a forwards, stepwise, weighted logistic regression procedure to calculate ORs and 95\% CIs for selected variables.

Results Preliminary findings suggest that among those initiating breastfeeding, $24.8 \%(n=60)$ practiced exclusive breastfeeding to 6 months. Inuit Canadians who speak primarily non-traditional languages in the household ( $\mathrm{OR}=0.47,95 \% \mathrm{CI} 0.27$ to 0.87$)$ and who report severe food insecurity $(\mathrm{OR}=0.67,95 \% \mathrm{CI} 0.30$ to 0.97$)$ were less likely to practice exclusive breastfeeding to 6 months in multivariable models.

Conclusions This is the first study to explore the role of food insecurity on breastfeeding practices among Canadian Inuit. This interesting finding deserves further exploration, particularly given the high prevalence of food insecurity in this population.

\section{P1-472 SOCIOECONOMIC STATUS AND SELF-RATED HEALTH: A NATIONWIDE STUDY FROM IRAN}

doi:10.1136/jech.2011.142976g.61

A Montazeri, ${ }^{*}$ J Sadighi, F Farzadi, S Omidvari, F Maftoon, A Aeenparast, K Jahangiri, M Vahdaninia. Iranian Institute for Health Sciences Research, ACECR, Tehran, Iran

Introduction Little is known about the relationship between socioeconomic factors and self-reported health in developing countries such as Iran. As part of a large study on health perception in Iran this relationship was investigated.

Methods This was a nationwide cross sectional study. A random sample of individuals aged between 18 and 65 were entered into the study. Respondents were asked to rate their own present health status on a 5-point scale. The record of demographic and socioeconomic data included age, gender, education, marital status, employment, income, place of residence, and chronic diseases. Logistic regression analysis was used to estimate ORs and $95 \%$ CIs for indicating of the contributing factors to self-reported health.

Results In all 27883 individuals were studied. The mean age of the respondents was $32.7(\mathrm{SD}=11.8)$ years, $71.5 \%$ rated their health as good or better than good while the remaining $28.5 \%$ indicated their health less than good and poor. The findings showed that in addition to some demographic variables, the most contributing factors to poor self-rated health were: income $[\mathrm{OR}=2.81$ for lower income], and presence of chronic diseases $[\mathrm{OR}=7.6,95 \% \mathrm{CI} 6.8$ to 7.9$]$. Living in smaller towns was found to contribute to a better self-reported health $[\mathrm{OR}=0.89$, $\mathrm{p}=0.01]$

Conclusion The findings indicated that there were inverse relationships between self-reported health and socioeconomic and ecological factors. The results suggest that social determinants of health play an important role in people's evaluation of their own health status. Policies need to address these concerns. 